\title{
Coumarin and Moracin Derivatives from Mulberry Leaves (Morus alba L.) with Soluble Epoxide Hydrolase Inhibitory Activity
}

\author{
Hong Xu Li ${ }^{1,2, \dagger}$, Myungsook Heo ${ }^{3, \dagger}$, Younghoon Go ${ }^{4} \mathbb{D}$, Young Soo Kim ${ }^{4}$, Young Ho Kim ${ }^{3}$, \\ Seo Young Yang ${ }^{3, *(D)}$ and Wei $\mathrm{Li}^{4, *(\mathbb{D})}$ \\ 1 Shenzhen Key Laboratory of Marine Bioresource and Eco-Environmental Science, College of Life Sciences \\ and Oceanography, Shenzhen University, Shenzhen 518060, China; charon0077@gmail.com \\ 2 College of Physics and Optoelectronic Engineering, Shenzhen University, Shenzhen 518060, China \\ 3 College of Pharmacy, Chungnam National University, Daejeon 34134, Korea; inyl1110@naver.com (M.H.); \\ yhk@cnu.ac.kr (Y.H.K.) \\ 4 Korean Medicine (KM) Application Center, Korea Institute of Oriental Medicine, Daegu 41062, Korea; \\ gotra827@kiom.re.kr (Y.G.); yskim527@kiom.re.kr (Y.S.K.) \\ * Correspondence: syyang@cnu.ac.kr (S.Y.Y.); liwei1986@kiom.re.kr (W.L.); Tel.: +82-42-821-5933 (S.Y.Y.); \\ +82-53-940-3874 (W.L.) \\ + These authors contributed equally to this work.
}

Academic Editor: Michiho Ito

Received: 20 July 2020; Accepted: 31 August 2020; Published: 31 August 2020

\begin{abstract}
This study identified three coumarins (1-3), and six moracin derivatives (4-9). The structures of these natural compounds were determined by the spectroscopic methods, including 1D and 2D NMR methods, and comparison with previous reported data. All of the isolated compounds were assessed for the effects on the soluble epoxide hydrolase (sEH) inhibitory activity. Among them, compounds 1-7 exhibited significant inhibitory effect with $100 \%$ inhibitory, with $\mathrm{IC}_{50}$ values of $6.9,0.2$, $15.9,1.1,1.2,9.9$, and $7.7 \mu \mathrm{M}$, respectively. A kinetic study revealed that compounds $\mathbf{1}-\mathbf{4}$, and $\mathbf{6}$ were competitive types of inhibitors, compounds 5 and 7 were mixed types of inhibitors. These results suggest that moracin and coumarin derivatives from mulberry leaves are significant $\mathrm{sEH}$ inhibitors.
\end{abstract}

Keywords: Morus alba; coumarin; moracin; soluble epoxide hydrolase (sEH)

\section{Introduction}

Inflammation is a normal protective biological response to irritation, injury, or infection. However, appropriate functioning of the immune system is necessary to maintain homeostasis. Prolonged inflammatory response often leads to the onset of chronic diseases, such as cancer, rheumatoid arthritis, and vascular disorders [1]. The inflammatory pathway producing eicosanoids, eicosanoids are a group of lipid mediators generated from arachidonic acid (ARA) by activity of cyclooxygenases (COX), lipoxygenases (LOX), and cytochrome P450 (CYP450) enzymes [2], i.e., signaling molecules derived from arachidonic acid, has been implicated in a variety of disorders, including stroke, hypertension, and renal diseases [3]. The pathway is mediated by cytochrome P450 enzymes and results in the production of two types of compounds, namely hydroxyeicosatetraenoic acids (HETEs) and epoxyeicosatrienoic acid isomers (EETs) [3]. Notably, soluble epoxide hydrolase (sEH) converts EETs to their corresponding diols (i.e., dihydroxyeicosatrienoic acids, DHETs), lead to reduce effects of EETs on the cardiovascular system through vasodilation, antimigration of vascular smooth muscle cells, and anti-inflammatory responses. Thus, $\mathrm{sEH}$ is considered a potential therapeutic target for the treatment of vascular diseases [4]. 
Morus, a genus of flowering plants in the family Moraceae, comprises 10-16 species of deciduous trees commonly known as mulberries. In this study, we mainly studied two types of compounds-coumarin and moracin. Coumarin belong to the benzopyrone type of compounds. The analogues of coumarin consist of various substances of phenolic class types. Biosynthesis of coumarins in plants follow the phenylpropanoid pathway [5]. Moreover, the distinctive and adaptable oxygen containing heterocyclic structure declared such an importance scaffold in coumarin compounds upon medicinal chemistry [6]. In the past decades, numerous derivatives of coumarins have been used as anticoagulant agents due to their resemblance to Vitamin K. In addition, coumarin analogues have been reported as inhibitors of sEH in previously reported literature [7], as well as many other inhibitor agents. The root bark, stem bark, and leaves of Morus alba, M. lhou, Morus macroura are the main sources for aryl-benzofuran derivatives, including the moracins. A large volume of research has been carried out on moracins and their derivatives, which has shown the pharmacological importance of this benzofuran heterocyclic nucleus. Morus alba L. (Moraceae) is widely cultivated in Asia and has been utilized in traditional medicine for decades. The M. alba herb is used to treat diabetes, inflammation, and obesity [8]. The benzofuran heterocycles are fundamental structural units in a wide range of biologically active natural products as well as synthetic materials. Moracin family is biologically active natural products containing benzofuran heterocycle as basic structural units. It has been shown that aryl-benzofurans isolated from this plant exhibit significant inhibitory activity against nitric oxide production [9]. Moreover, our previous studies indicated that several aryl benzofuran and flavonol derivatives displayed strong activity in the treatment of obesity and melanogenesis $[10,11]$. Hence, M. alba is a potential source of numerous natural products with important biological activities.

\section{Results and Discussion}

\subsection{Isolation and Structural Elucidation}

In the present study, nine compounds were isolated from the $\mathrm{MeOH}$ extract of M. alba (Figure 1). The structures of the compounds were determined by various spectroscopic methods, including 1D and 2D nuclear magnetic resonance to give aesculetin (1) [12], scopoletin (2) [13], scopoline (3) [14], moracin B (4) [15], moracin J (5) [16], moracin M (6) [17], moracin M 3'-O- $\beta$-glucopyranoside (7) [18], moracin M 6- $\beta$-D-glucopyranoside (8) [19], and mulberroside F (9) [20] (See Supplementary Materials).<smiles>[R]c1cc2ccc(=O)oc2cc1[R]</smiles>

1. $\mathrm{R}_{1}=\mathrm{OH} \quad \mathrm{R}_{2}=\mathrm{OH}$

2. $\mathrm{R}_{1}=\mathrm{OH} \quad \mathrm{R}_{2}=\mathrm{OCH}_{3}$

3. $\mathrm{R}_{1}=\mathrm{OGIC} \quad \mathrm{R}_{2}=\mathrm{OCH}_{3}$<smiles>[R]c1cc(O)cc(-c2cc3cc([R])c([R])cc3o2)c1</smiles>

4. $\mathrm{R}_{1}=\mathrm{OH} \quad \mathrm{R}_{2}=\mathrm{OCH}_{3} \quad \mathrm{R}_{3}=\mathrm{OCH}_{3}$

5. $\mathrm{R}_{1}=\mathrm{OCH}_{3} \quad \mathrm{R}_{2}=\mathrm{OH} \quad \mathrm{R}_{3}=\mathrm{OH}$

6. $\mathrm{R}_{1}=\mathrm{H} \quad \mathrm{R}_{2}=\mathrm{OH} \quad \mathrm{R}_{3}=\mathrm{OH}$

7. $\mathrm{R}_{1}=\mathrm{OH} \quad \mathrm{R}_{2}=\mathrm{H} \quad \mathrm{R}_{3}=\mathrm{OGlC}$

8. $\mathrm{R}_{1}=\mathrm{OGlC} \quad \mathrm{R}_{2}=\mathrm{H} \quad \mathrm{R}_{3}=\mathrm{OH}$

9. $\mathrm{R}_{1}=\mathrm{H} \quad \mathrm{R}_{2}=\mathrm{OGIC} \quad \mathrm{R}_{3}=\mathrm{OGIC}$

Figure 1. Structures of compounds 1-9 isolated from M. alba.

\subsection{Bioassays}

Over the last 20 years, sEH has been linked to numerous pathological conditions, including cardiovascular and neurological diseases [3]. Additionally, its role in the central nervous system disorders has also been established. Thus, inhibition of this enzyme shows robust therapeutic potential. In the present study, the candidate inhibitory compounds 1-7 were subjected to an enzyme kinetics evaluation to access the binding mode between the receptor and ligands. The enzyme inhibition 
properties of the derivatives were modeled using double-reciprocal plots (Lineweaver-Burk and Dixon analyses). It was determined that compounds 1-4 and 6 were competitive inhibitors. The analysis of the Lineweaver-Burk plot suggested that increasing the inhibitor concentration increased the $K_{\mathrm{m}}$ values without affecting $V_{m}$ [21]. Moreover, the $K_{\mathrm{i}}$ values for compounds 1-4 and $\mathbf{6}$ were calculated from the Dixon plots and were equal to $1.2,0.3,5.4,1.0$, and $1.5 \mu \mathrm{M}$, respectively. Compounds 5 and 7 were found to be mixed inhibitors. Analysis of the Lineweaver-Burk plot indicated that increasing the inhibitor concentration increased $K_{\mathrm{m}}$, but decreased the $V_{\mathrm{m}}$ values [21]. The $K_{i}$ values for compounds 5 and 7 were also calculated from the Dixon at 2.1 and $5.8 \mu \mathrm{M}$, respectively (Figure 2).

The sEH inhibitory effects of compounds 1-9 isolated from $M$. alba were subsequently investigated using recombinant human $\mathrm{SEH}$ incubated in the presence of PHOME, which is an artificial substrate for fluorescence detection (Table 1). All of the isolated derivatives were tested in $100 \mu \mathrm{M}$ solutions against the enzyme. Notably, compounds 1-7 exhibited as 100\% inhibitory activity against sEH, while analogs 8 and 9 displayed insignificant effects $(<50 \%)$. In the past, phytochemistry and bioactivity studies primarily focused on aryl benzofuran derivatives [22]. The sEH inhibitory activity of coumarins established in the present work provides a valuable platform for further bioactivity evaluation. It is noteworthy that coumarin analogs have low molecular weights and show high degree of lipid solubility, facilitating transmembrane diffusion [23]. We determined that compound 1 had a lower $\mathrm{IC}_{50}$ value $(6.9 \mu \mathrm{M})$ than derivative $3(15.9 \mu \mathrm{M})$. Moreover, derivative 2 not only displayed robust $\mathrm{sEH}$ inhibitory effects, but also exhibited the lowest $\mathrm{IC}_{50}$ value $(0.2 \mu \mathrm{M})$ out of all nine isolated compounds. The presence of three types of functional groups in the molecules, specifically $-\mathrm{OH},-\mathrm{OCH}_{3}$, and -OGlc, particularly drew our attention. Both the inhibitory effects and the $\mathrm{IC}_{50}$ values were considerably affected by different functional groups. Replacing the $-\mathrm{OH}$ moiety at the $\mathrm{C}-6$ position in compound 1 with a $-\mathrm{OCH}_{3}$ group led to a 34-fold decrease in the $\mathrm{IC}_{50}$ value than before. On the other hand, the presence of some functional groups, e.g., -OGlc, resulted in an increase in the $\mathrm{IC}_{50}$ value. Similarly, to the coumarin derivatives, the moracin analogs contain the same three types of functional groups (i.e., $-\mathrm{OH},-\mathrm{OCH}_{3}$, and -OGlc). Hence, the structural properties and the determined sEH inhibitory effects of compounds 1-9 allowed us to investigate the structure-activity relationship (Figure 3).

Based on the exhibited inhibitory effects, the aryl benzofurans could be divided into three categories. The first category included compounds 4 and 5, while the second, derivatives 6 and 7 . All compounds in this group displayed inhibitory activity of $=100 \%$ with $\mathrm{IC}_{50}$ values of $1.1,1.2,9.9$, and $7.7 \mu \mathrm{M}$, respectively. The last category included derivatives $\mathbf{8}$ and $\mathbf{9}$ with low inhibitory activities of $18.3 \%$ and $17.1 \%$, respectively. The classification was not only based on the $\mathrm{IC}_{50}$ values, but also on the presence of specific functional groups. Compounds 7, 8 and 9 all contain a -OGlc functional group; however, they display various inhibitory effects and $\mathrm{IC}_{50}$ values. It was speculated that the dissimilarities were a consequence of different functionalities on the A or B ring in the structures. The obtained results suggested that in the case of moracin compounds, a -OGlc moiety on the A ring decreased the $\mathrm{sEH}$ inhibitory effect. However, the presence of this functionality on the B ring had a minor effect on the inhibitory activity. The difference between the structures of isomers 4 and 5 , which possess identical B rings, is the position of the substituents at the C-5 and C- 6 positions. The comparison of the data for these compounds revealed that the $-\mathrm{OCH}_{3}$ group plays a significant role in sEH inhibition, resulting in both an increase in the inhibitory effects and a decrease in the $\mathrm{IC}_{50}$ values. Furthermore, for compounds 6 and 7, the replacement of the $-\mathrm{OH}$ moiety with the $-\mathrm{OCH}_{3}$ group led to an increase in the $\mathrm{IC}_{50}$ values. Overall, it was established that the $-\mathrm{OCH}_{3}$ functionality increased the sEH inhibitory effects most significantly, followed by the $-\mathrm{OH}$ group. Moreover, the presence of the-OGlc moiety resulted in an increase in the $\mathrm{IC}_{50}$ values for some compounds or a decrease in the inhibitory effects for other derivatives. 


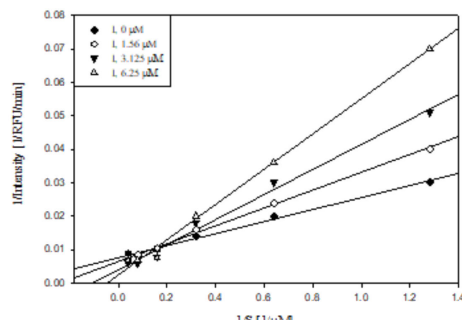

A

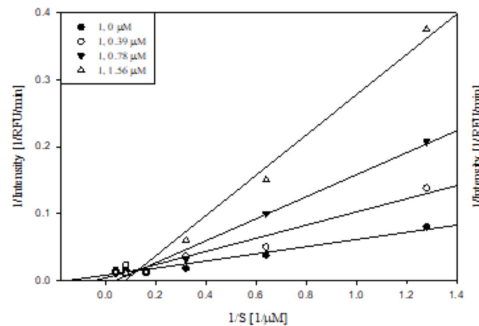

D

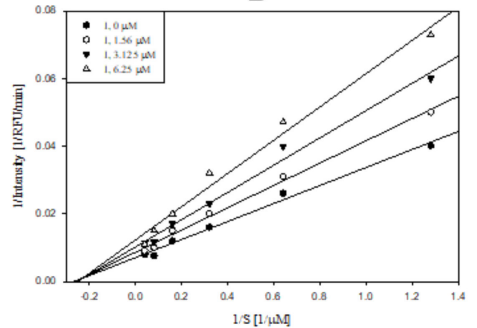

G

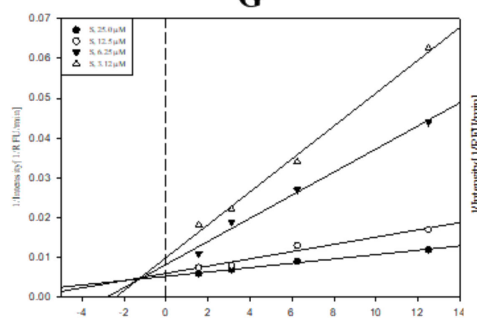

a

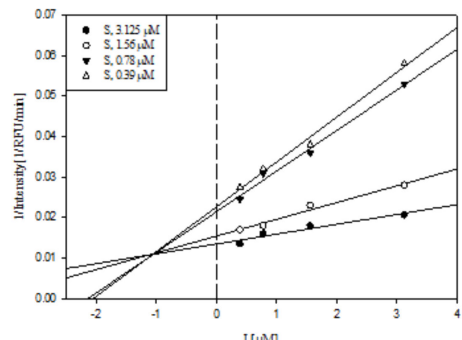

I $[\mathrm{MM}]$

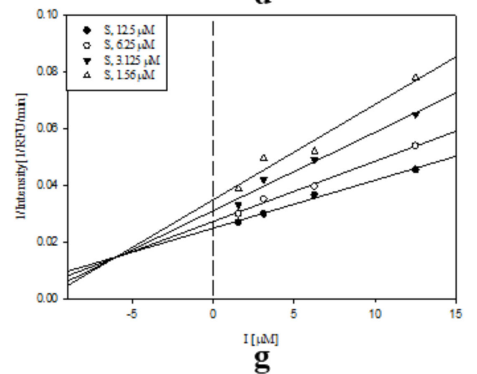

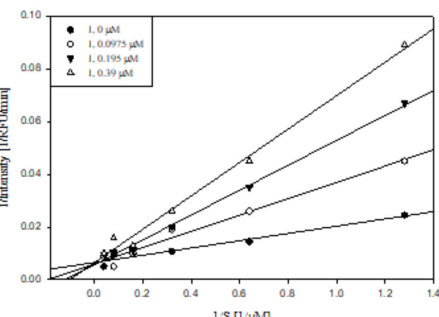

B

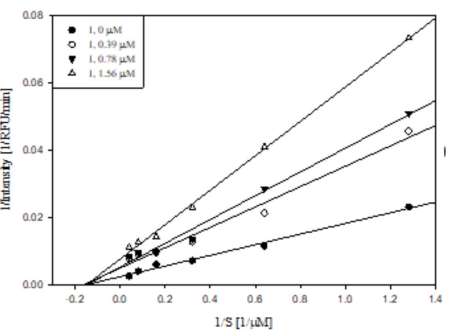

E

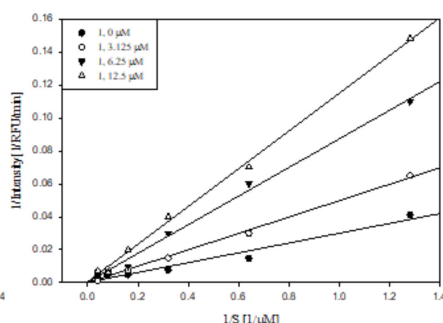

C

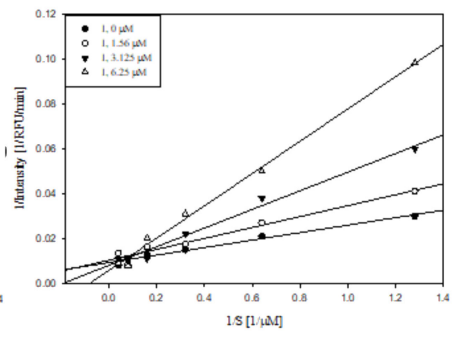

F

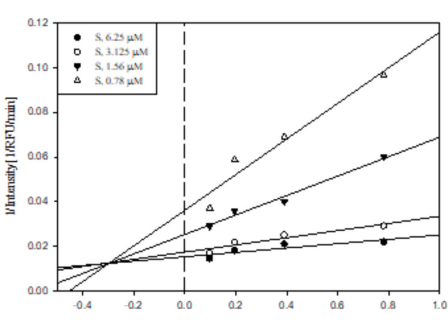

I

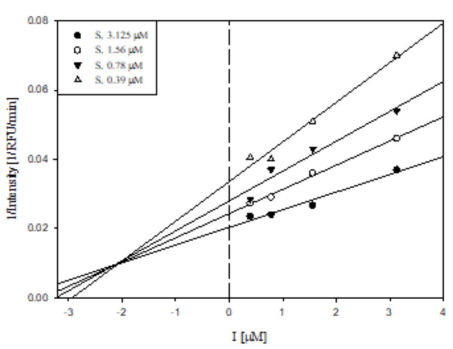

e

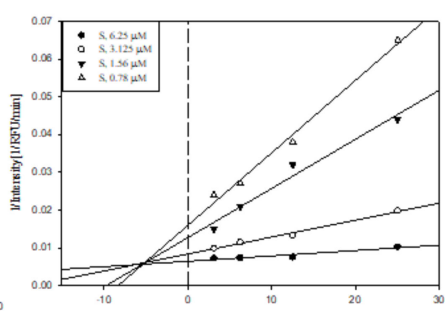

Itwal

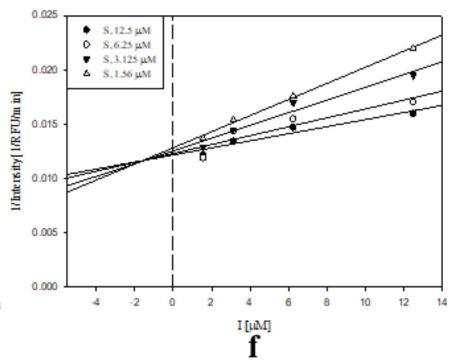

Figure 2. Study of the binding mechanisms between compounds 1-7 and sEH: (A-G) Lineweaver-Burk plots for compounds 1-7, respectively; (a-g) Dixon plots for compounds 1-7, respectively. Data are the mean of three experiments carried out in triplicate and were determined by one-way analysis of variance, followed by Dunnett's multiple comparison test, $p<0.05$ versus control. 
Table 1. Inhibitory effects of isolated compounds $\mathbf{1 - 9}$.

\begin{tabular}{|c|c|c|c|}
\hline \multicolumn{4}{|c|}{ Inhibition of Compounds on sEH } \\
\hline Compounds & $100 \mu \mathrm{M}(\%)$ & $\mathrm{IC}_{50}(\mu \mathrm{M})$ & Type $(K i, \mu \mathrm{M})$ \\
\hline 1 & $=100$ & $6.9 \pm 0.5$ & competitive $(1.2 \pm 0.4)$ \\
\hline 2 & $=100$ & $0.2 \pm 0.1$ & competitive $(0.3 \pm 0.1)$ \\
\hline 3 & $=100$ & $15.9 \pm 0.4$ & competitive $(5.4 \pm 0.7)$ \\
\hline 4 & $=100$ & $1.1 \pm 0.1$ & competitive $(1.0 \pm 0.3)$ \\
\hline 5 & $=100$ & $1.2 \pm 0.1$ & mixed $(2.1 \pm 0.6)$ \\
\hline 6 & $=100$ & $9.9 \pm 2.2$ & competitive $(1.5 \pm 0.2)$ \\
\hline 7 & $=100$ & $7.7 \pm 0.1$ & mixed $(5.8 \pm 0.1)$ \\
\hline 8 & $18.3 \pm 4.2$ & N.T $b$ & N.T \\
\hline 9 & $17.1 \pm 3.3$ & N.T & N.T \\
\hline AUDA $^{a}$ & & $11.6 \pm 0.3(\mathrm{nM})$ & \\
\hline
\end{tabular}

sEH activity was expressed as the percentage of control activity. Values represent means $\pm \operatorname{SD}(n=3)$. ${ }^{\text {a }}$ Positive control. ${ }^{b}$ N.T: Not Tested.

\begin{tabular}{|c|c|c|c|}
\hline & C-6 & C-7 & $\mathrm{IC}_{50}$ \\
\hline 1 & $-\mathrm{OH}$ & $-\mathrm{OH}$ & $6.9 \pm 0.5$ \\
\hline 2 & $-\mathrm{OCH}_{3}$ & $-\mathrm{OH}$ & $0.2 \pm 0.1$ \\
\hline 3 & $-\mathrm{OCH}_{3}$ & -OGlc & $15.9 \pm 0.4$ \\
\hline
\end{tabular}

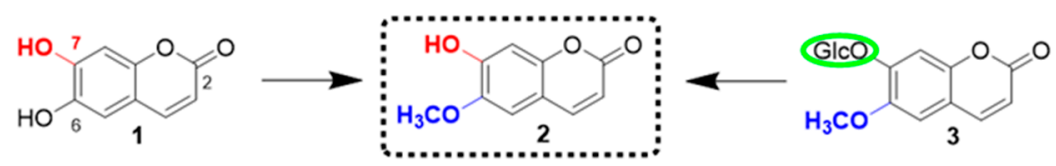

\begin{tabular}{cccc}
\hline & $\mathbf{C}-\mathbf{5}$ & $\mathbf{C}-6$ & IC $_{50}$ \\
\hline$=\mathbf{4}$ & $-\mathrm{OH}$ & $-\mathrm{OCH}_{3}$ & $1.1 \pm 0.1$ \\
$\mathbf{5}$ & $-\mathrm{OCH}_{3}$ & $-\mathrm{OH}_{2}$ & $1.2 \pm 0.1$ \\
$\mathbf{6}$ & $-\mathrm{H}$ & $-\mathrm{OH}$ & $9.9 \pm 2.2$ \\
$\mathbf{7}$ & $-\mathrm{OH}$ & $-\mathrm{H}$ & $7.7 \pm 0.1$ \\
$\mathbf{8}$ & $-\mathrm{OGlc}$ & $-\mathrm{OH}$ & N.T \\
$\mathbf{9}$ & $-\mathrm{H}$ & $-\mathrm{OGl}$ & N.T \\
\hline
\end{tabular}

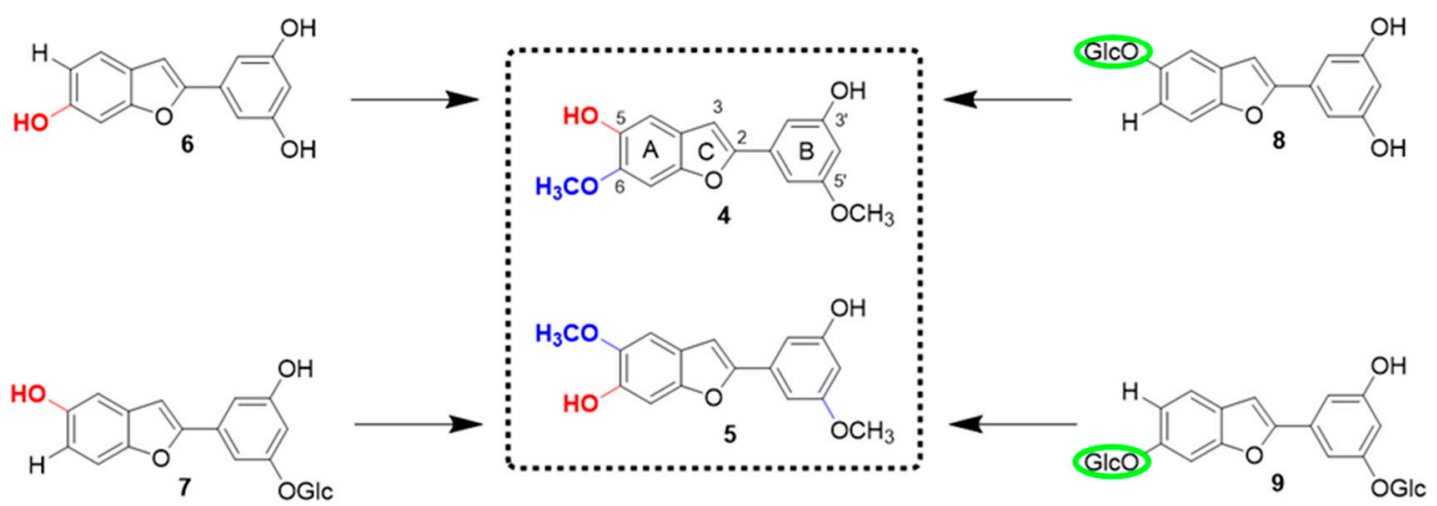

Figure 3. Identification of the structure-activity relationship based on the soluble epoxide hydrolase (she) inhibitory effects of compounds isolated from the leaves of M. alba.

Previous studies have reported a crystal structure showing the interaction between $\mathrm{sEH}$ and its potent inhibitor 3-phenylglutaric acid (Protein Data Bank (PDB) code: 3ANS) [24,25]. Based on 
this information, we investigated, the binding interactions of compound 2, 4, and 5, which were effective on the sEH inhibition, with amino acid residues in $\mathrm{sEH}$ by protein-ligand docking simulation using AutoDock Vina and LigPlot+ software (Figure 4). Molecular docking simulation indicated that sEH may interact with compound 2, 4, and 5 by forming several hydrogen bonds and hydrophobic interactions (Figure 4 and Table 2). The pharmacophore analysis suggested that compound 2 created a hydrophobic interaction and a hydrogen bond with the two amino acids Asp335 and Trp466 [7], respectively, among the sEH catalytic triads (Asp335, Tyr383, and Trp466), and a strong $\pi-\pi$ interaction with Trp336, such like 3-phenylglutaric acid [24,25]. While compound 4 and 5 seem to block the catalytic pocket of sEH by the interaction of A ring with all catalytic triads and C ring with Ser407, Leu408, Ser415, Leu417, and Met419, locating on the opposite side of Trp336. These binding sites suggest that these amino acid sequences are crucial receptors in the inhibition of sEH enzyme activity. The interaction with catalytic triads were known to conservatively contribute to stabilizing the binding between sEH and its various inhibitors [24].

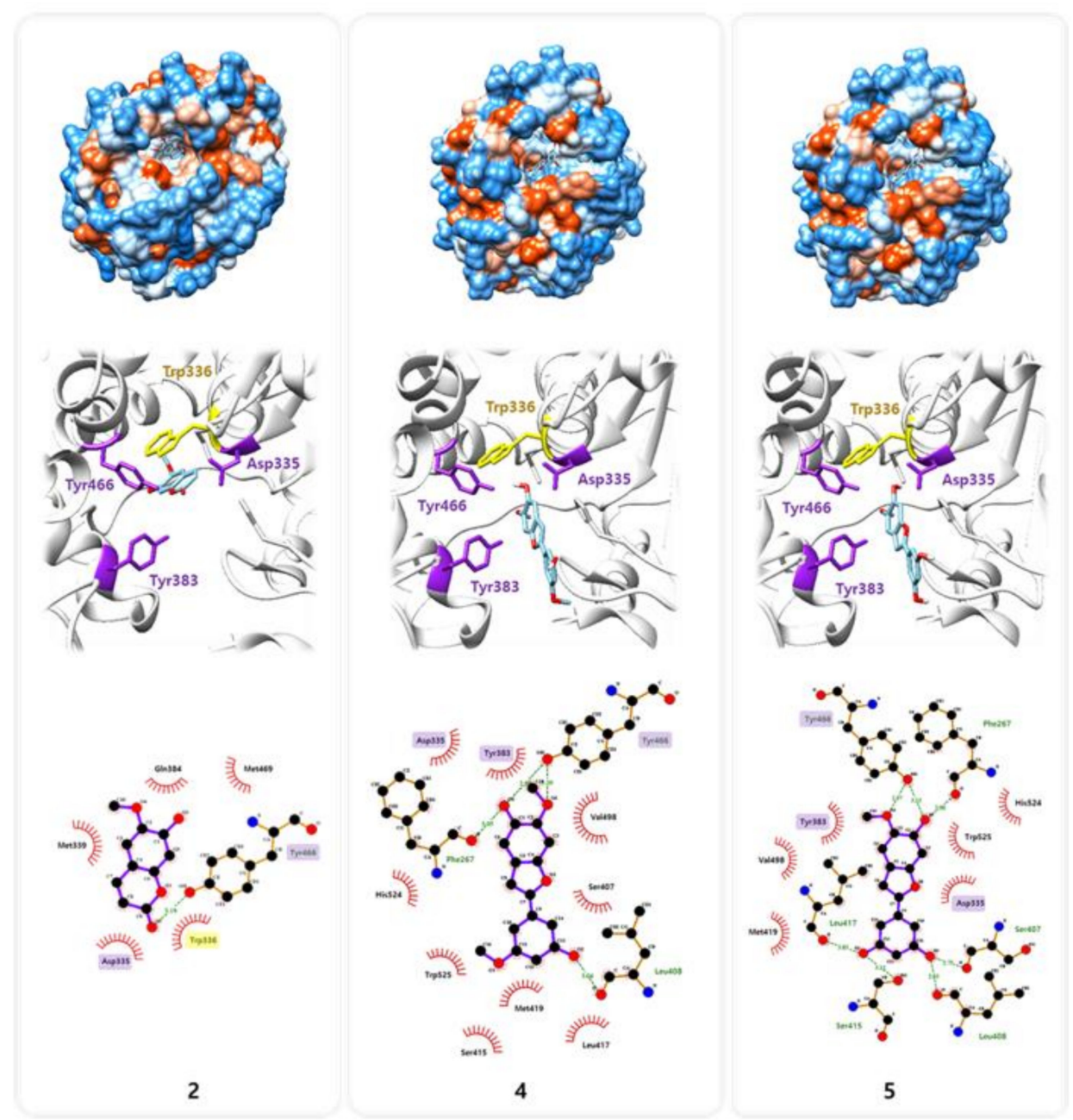

Figure 4. Molecular docking simulation of compounds 2, 4, and 5 into the predicted binding site of sEH. 
Table 2. Pharmacophore analysis between sEH and compounds 2, 4, and 5.

\begin{tabular}{|c|c|c|}
\hline \multirow{2}{*}{ Compounds } & \multicolumn{2}{|c|}{ Receptor $^{a}$} \\
\hline & Hydrogen Bonds (Å) & Hydrophobic Interactions \\
\hline 2 & Y466 (3.18) & D335, W336, M339, Q384, M469 \\
\hline 4 & F267 (3.05), L408 (3.04), Y466 $(2.88,3.10)$ & $\begin{array}{c}\text { D335, Y383, S407, S415, L417, M419, } \\
\text { V498, H524, W525 }\end{array}$ \\
\hline 5 & $\begin{array}{c}\text { F267 (2.90), L408 (2.83), S407 (2.75), S415 } \\
\text { (3.13), L417 (3.03), Y466 }(2.97,3.13)\end{array}$ & D335, Y383, M419, V498, H524, W525 \\
\hline
\end{tabular}

\section{Conclusions}

In the present study, nine compounds (1-9) were isolated from the $\mathrm{MeOH}$ extract of M. alba. The analysis of the sEH inhibitory effects indicated that coumarin and aryl benzofuran derivatives show potential biological activities. Inhibitory activity of $=100 \%$ was noted for some compounds, showing the potential of coumarins and aryl benzofurans for the treatment of inflammatory disorders. Notably, a remarkably low $\mathrm{IC}_{50}$ value was determined in the case of compound $2(0.2 \mu \mathrm{M})$. Nonetheless, further research is necessary to confirm compounds 1-7 as potential drug candidates for the treatment of inflammatory diseases. Therefore, we identified some bioactive compounds corresponding to the traditional treatment usage, which might prove by in vitro methods, molecular docking simulation, and pharmacophore analysis. As a rich natural product resource of Moraceae family, it is important to study some compounds which might collaborate working with each other and apply a better choice for the patients, especially with some chronical physical disorders. Thus, a low cost and toxicity treatment strategy could provide for more needed people.

\section{Materials and Methods}

\subsection{General Information}

Optical rotations were determined using a Jasco DIP-370 automatic polarimeter. The NMR spectra were recorded using a JEOL ECA 600 spectrometer $\left({ }^{1} \mathrm{H}, 600 \mathrm{MHz} ;{ }^{13} \mathrm{C}, 150 \mathrm{MHz}\right)$, The LCQ advantage trap mass spectrometer (Thermo Finnigan, San Jose, CA, U.S.A.) was equipped with an electrospray ionization (ESI) source, and High-resolution electrospray ionization mass spectra (HR-ESI-MS) were obtained using an Agilent 6530 Accurate-Mass Q-TOF LC/MS system. Preparative HPLC was performed using a GILSON 321 pump, 151 UV/VIS detector (Gilson, VILLIERS-LE-BEL, France), and RStech HECTOR-M C ${ }_{18}$ column (5-micron, $250 \times 21.2 \mathrm{~mm}$ ) (RS Tech Crop, Chungju, South Korea). Column chromatography was performed using a silica gel (Kieselgel 60, 70-230, and 230-400 mesh, Merck, Darmstadt, Germany), YMC RP-18 resins, and thin layer chromatography (TLC) was performed using pre-coated silica-gel $60 \mathrm{~F}_{254}$ and $\mathrm{RP}-18 \mathrm{~F}_{254} \mathrm{~S}$ plates (both $0.25 \mathrm{~mm}$, Merck, Darmstadt, Germany).

\subsection{Plant Material}

Dried leaves of Morus alba L. were purchased from herbal company, Naemome Dah, Ulsan, Korea, in September 2015. Its scientific name was identified by one of author (Prof. Young Ho Kim). A voucher specimen (CNU 16004-1) was deposited at the Herbarium of College of Pharmacy, Chungnam National University, Republic of Korea.

\subsection{Extraction and Isolation}

The dried leaves of $M$. alba $(2.9 \mathrm{~kg})$ was refluxing extraction with $\mathrm{MeOH}(10 \mathrm{~L} \times 3)$ times. The total extraction $(384.0 \mathrm{~g})$ of $\mathrm{MeOH}$ was suspended in deionized water and partitioned with $\mathrm{n}$-hexane, yielding $\mathrm{n}$-hexane fraction $(1 \mathrm{~A}, 166.0 \mathrm{~g})$ and water fraction. Then the water fraction was partitioned 
sequential with EtOAc and n-BuOH, yielding EtOAc fraction (1B, $16.1 \mathrm{~g}), n$-BuOH fraction $(1 \mathrm{C}, 65.0 \mathrm{~g})$ and water fraction $(1 \mathrm{D}, 94.0 \mathrm{~g})$. The EtOAc fraction was subjected to a silica gel column chromatography with a gradient of $\mathrm{CHCl}_{3}$ : MeOH: water (20:1:0, 15:1:0, 10:1:0, 8:1:0, 6:1:0.1, 4:1:0.1, 2:1:0.1, and 100\% $\mathrm{MeOH}$ ) to give 8 fractions (1B-1-1B-8). The fraction 1B-1 was performed separation with a gradient of $\mathrm{MeOH}$ : water (1:4, 1:3, 1:2, 1:1, and $\mathrm{MeOH})$ by middle pressure liquid chromatography (MPLC) using $\mathrm{C}_{18}$ column to give 5 fractions (1B-1-1-1B-1-4). Subfraction 1B-1-2 was separated by a Sephadex LH-20 column and eluted by $\mathrm{MeOH}$ and its subfractions were isolated by prep-HPLC to give compounds 1 (3.2 mg) and 2 (10.1 mg). Subfraction 1B-1-4 was separated by a Sephadex LH-20 column and eluted by $\mathrm{MeOH}$ and its subfraction was isolated by prep-HPLC to give compound $4(6.1 \mathrm{mg})$. The fraction 1B-4 was isolated with a gradient of MeOH: water (1:4, 1:3, 1:2, 1:1, and MeOH) by MPLC using $\mathrm{C}_{18}$ column to give 3 fractions (1B-4-1-1B-4-3). The fraction 1B-5 was isolated with a gradient of $\mathrm{MeOH}$ : water $(1: 3,1: 2,1: 1$, and $\mathrm{MeOH})$ by MPLC using $\mathrm{C}_{18}$ column to give 4 fractions (1B-5-1-1B-5-4). Subfraction 1B-5-2 was separated by a Sephadex LH-20 column and eluted by $\mathrm{MeOH}$ and its subfraction was isolated by prep-HPLC to give compound $5(6.5 \mathrm{mg})$. The fraction 1B-8 was isolated with a gradient of $\mathrm{MeOH}$ : water (1:2, 1:1, and $\mathrm{MeOH})$ by MPLC using $\mathrm{C}_{18}$ column to give 9 fractions (1B-8-1-1B-8-9). Subfraction 1B-8-5 was separated by a Sephadex LH-20 column and eluted by $\mathrm{MeOH}$ and its subfraction was isolated by prep-HPLC to give compound $3(1.1 \mathrm{mg})$. Subfraction 1B-8-7 was separated by a Sephadex LH-20 column and eluted by $\mathrm{MeOH}$ and its subfraction was isolated by prep-HPLC to give compound 6 (20.1 mg). Subfraction 1B-8-8 was separated by a Sephadex LH-20 column and eluted by $\mathrm{MeOH}$ and its subfraction was isolated by prep-HPLC to give compound $8(9.7 \mathrm{mg})$. Subfraction 1B-8-9 was separated by a Sephadex LH-20 column and eluted by $\mathrm{MeOH}$ and its subfraction was isolated by prep-HPLC to give compound 7 (6.1 mg). The water fraction was subjected on a HP-20 column, and eluted with water, $25 \% \mathrm{MeOH}, 50 \% \mathrm{MeOH}, 75 \% \mathrm{MeOH}$, and $100 \% \mathrm{MeOH}$, yield 5 fractions (1D-1-1D-5). Fraction 1D-2 and 1D-3 were combined (1D-2-1), and isolated with a gradient of MeOH: water (1:4, 1:3, 1:2, 1:1, and MeOH) by MPLC using $C_{18}$ column to give 5 fractions (1D-2-1-1-1D-2-1-5). Subfraction 1D-2-1-2 was separated by a Sephadex LH-20 column and eluted by $\mathrm{MeOH}$ and its subfraction was isolated by prep-HPLC to give compound $\mathbf{9}(17.8 \mathrm{mg})$.

\section{4. sEH Assay}

The soluble epoxide hydrolase (sEH) assay, bis-Tris methane (B9754), and albumin (A8806) were purchased from Sigma Aldrich (St. Louis, MO, USA). Human recombinant soluble epoxide hydrolases (sEH, 10011669), and 3-phenyl-cyano(6-methoxy-2-naphthalenyl)methyl ester-2-oxiraneacetic acid (PHOME) (10009134) were purchased from the Cayman Chemical Company (Cayman, MI, USA). The 96-well white plate was purchased from Costar (Corning, NY, USA). The fluorescence intensity measurements were conducted utilizing the Tecan infinite F200 microplate reader (Tecan, Mannedorf, Switzerland).

The enzymatic assays were carried out according to previously reported methods, with some modifications [3]. A $130 \mu \mathrm{L}$ aliquot of recombinant human $\mathrm{sEH}(12.15 \mathrm{ng} / \mathrm{mL})$ was diluted with the buffer ( $25 \mathrm{mM}$ bis-Tris- $\mathrm{HCl}$ containing $0.1 \mathrm{mg} / \mathrm{mL}$ BSA, $\mathrm{pH}$ 7.0). Subsequently, $20 \mu \mathrm{L}$ of $\mathrm{MeOH}$ and $50 \mu \mathrm{L}$ of PHOME $(10 \mu \mathrm{M})$ were added. The amount of the substrate converted to the product by the enzyme was measured by fluorescence photometry $(330 \mathrm{~nm}$ excitation filter and $465 \mathrm{~nm}$ emission filter), according to the following equation:

$$
\text { Enzyme activity }(\%)=\left[\mathrm{S}_{40}-\mathrm{S}_{0} / \mathrm{C}_{40}-\mathrm{C}_{0}\right] \times 100
$$

where $C_{40}$ and $S_{40}$ are the fluorescence of the control and inhibitor after $40 \mathrm{~min}$, while $\mathrm{S}_{0}$ and $\mathrm{C}_{0}$ indicate the fluorescence of the inhibitor and control at $0 \mathrm{~min}$, respectively. In the study, 12-(3-adamantan-1-yl-ureido)-dodecanoic acid (AUDA) was employed as a positive control, and 10\% of $\mathrm{MeOH}$ was used as blank control. The $\mathrm{IC}_{50}$ values were measured according to the concentration over $50 \%$ of inhibition ratio. Then various concentrations of substrate were diluted in orders to calculate 
$\mathrm{IC}_{50}$ values using Hyperbola, single rectangular formula $\mathrm{y}=\mathrm{ax} /(\mathrm{b}+\mathrm{x})$ to yield coefficient standard error, $\mathrm{a}$ and $\mathrm{b}, \mathrm{IC}_{50}=50 \times \mathrm{b} / \mathrm{a}-50$.

\section{5. sEH Kinetic Assay}

Kinetic assays were carried out under steady-state conditions. The enzyme inhibition properties of the components were modeled using double-reciprocal plots (Lineweaver-Burk and Dixon analyses). Briefly, $50 \mu \mathrm{L}$ of sEH and $20 \mu \mathrm{L}$ of various concentrations of the analyzed compounds in $\mathrm{MeOH}$ were added into each well of a 96-well plate. $80 \mu \mathrm{L}$ of a $25 \mathrm{mM}$ bis-Tris- $\mathrm{HCl}$ buffer ( $\mathrm{pH} 7.0$ ) containing $0.1 \%$ BSA and $50 \mu \mathrm{L}$ of the PHOME substrate $(5-80 \mu \mathrm{M})$ were then added into each well. The enzymatic reaction was initiated at $37^{\circ} \mathrm{C}$ and the formation of the products resulting from the hydrolysis of the substrates was monitored over $30 \mathrm{~min}$ at excitation and emission of 330 and $465 \mathrm{~nm}$, respectively [26].

\subsection{Molecular Docking Simulation and Pharmacophore Analysis}

The compounds $\mathbf{2}, \mathbf{4}$, and 5 were docked onto the catalytic pocket of sEH retrieved from the Protein Data Bank (www.rcsb.org, PDB code: 3ANS) [24], using AutoDock Vina integrated with UCSF Chimera v1.14 [27]. Subsequently, the interaction between sEH and each compound was analyzed based on the docking simulation result using LigPlot+ v1.4.5 [28]. Amino acid residues involved in the interactions were indicated with red (hydrophobic interactions) and green (H-bonds).

Supplementary Materials: The following are available online, NMR data of compounds 1-9.

Author Contributions: The list authors contributed to this work as follows: H.X.L. and M.H. performed the isolation, structure elucidation of the constituents, conducted the bioassay experiments, and prepared the manuscript. S.Y.Y. assisted the experiments and prepared the manuscript; Y.S.K. contributed to the molecular docking simulation and pharmacophore analysis; Y.H.K. and Y.G. contributed to the revision of this manuscript. The whole research was performed based on the planning of W.L. All authors have read and agreed to the published version of the manuscript.

Funding: This research was funded by Korean Institute of Oriental Medicine the Ministry of Education, Science and Technology (MEST), grant number [KSN2013230].

Conflicts of Interest: The authors declare no conflict of interest.

\section{References}

1. Jung, S.; Lee, M.S.; Choi, A.J.; Kim, C.T.; Kim, Y. Anti-inflammatory effects of high hydrostatic pressure extract of mulberry (morus alba) fruit on lps-stimulated raw264. 7 cells. Molecules 2019, 24, 1425. [CrossRef] [PubMed]

2. Wagner, K.M.; McReynolds, C.B.; Schmidt, W.K.; Hammock, B.D. Soluble epoxide hydrolase as a therapeutic target for pain, inflammatory and neurodegenerative diseases. Pharmacol. Ther. 2017, 180, 62-76. [CrossRef] [PubMed]

3. Zarriello, S.; Tuazon, J.; Corey, S.; Schimmel, S.; Rajani, M.; Gorsky, A.; Incontri, D.; Hammock, B.D.; Borlongan, C.V. Humble beginnings with big goals: Small molecule soluble epoxide hydrolase inhibitors for treating cns disorders. Prog. Neurobiol. 2019, 172, 23-39. [CrossRef] [PubMed]

4. Bai, M.M.; Shi, W.; Tian, J.M.; Lei, M.; Kim, J.H.; Sun, Y.N.; Kim, Y.H.; Gao, J.M. Soluble epoxide hydrolase inhibitory and anti-inflammatory components from the leaves of eucommia ulmoides oliver (duzhong). J. Agric. Food Chem. 2015, 63, 2198-2205. [CrossRef]

5. Bourgaud, F.; Hehn, A.; Larbat, R.; Doerper, S.; Gontier, E.; Kellner, S.; Matern, U. Biosynthesis of coumarins in plants: A major pathway still to be unravelled for cytochrome p450 enzymes. Phytochem. Rev. 2006, 5, 293-308. [CrossRef]

6. Detsi, A.; Kontogiorgis, C.; Hadjipavlou-Litina, D. Coumarin derivatives: An updated patent review (2015-2016). Expert Opin. Ther. Pat. 2017, 27, 1201-1226. [CrossRef]

7. Khanh, P.N.; Spiga, O.; Trezza, A.; Kim, Y.H.; Cuong, N.M. Coumarins isolated from Murraya paniculata in vietnam and their inhibitory effects against enzyme soluble epoxide hydrolase (sEH). Planta Med. 2016, 3, e68-e71. [CrossRef] 
8. Tran, H.N.K.; Nguyen, V.T.; Kim, J.A.; Rho, S.S.; Woo, M.H.; Choi, J.S.; Lee, J.-H.; Min, B.S. Anti-inflammatory activities of compounds from twigs of morus alba. Fitoterapia 2017, 120, 17-24. [CrossRef]

9. Yang, Z.-G.; Matsuzaki, K.; Takamatsu, S.; Kitanaka, S. Inhibitory effects of constituents from morus alba var. Multicaulis on differentiation of 3t3-11 cells and nitric oxide production in raw264. 7 cells. Molecules 2011, 16, 6010-6022. [CrossRef]

10. Li, H.X.; Jo, E.; Myung, C.S.; Kim, Y.H.; Yang, S.Y. Lipolytic effect of compounds isolated from leaves of mulberry (morus alba 1.) in 3t3-11 adipocytes. Nat. Prod. Res. 2018, 32, 1963-1966. [CrossRef]

11. Li, H.X.; Park, J.; Su, X.; Kim, K.; Kang, J.; Kim, Y.; Yang, S. Identification of anti-melanogenesis constituents from morus alba 1. Leaves. Molecules 2018, 23, 2559. [CrossRef] [PubMed]

12. Wu, H.; Su, Z.; Yili, A.; Xiao, Z.; Hang, B.; Aisa, H. Isolation of esculetin from cichorium glandulosum by high-speed countercurrent chromatography. Chem. Nat. Compd. 2007, 43, 109. [CrossRef]

13. Adfa, M.; Yoshimura, T.; Komura, K.; Koketsu, M. Antitermite activities of coumarin derivatives and scopoletin from protium javanicum burm. f. J. Chem. Ecol. 2010, 36, 720-726. [CrossRef] [PubMed]

14. Tsukamoto, H.; Hisada, S.; Nishibe, S. Coumarin and secoiridoid glucosides from bark of olea africana and olea capensis. Chem. Pharm. Bull. 1985, 33, 396-399. [CrossRef]

15. Takasugi, M.; Nagao, S.; Masamune, T.; Shirata, A.; Takahashi, K. Structure of moracin a and b, new phytoalexins from diseased mulberry. Tetrahedron Lett. 1978, 7, 1239-1240. [CrossRef]

16. Zhang, L.; Tao, G.; Chen, J.; Zheng, Z.-P. Characterization of a new flavone and tyrosinase inhibition constituents from the twigs of Morus alba L. Molecules 2016, 21, 1130. [CrossRef] [PubMed]

17. Jeong, S.H.; Ryu, Y.B.; Curtis-Long, M.J.; Ryu, H.W.; Baek, Y.S.; Kang, J.E.; Lee, W.S.; Park, K.H. Tyrosinase inhibitory polyphenols from roots of morus lhou. J. Agric. Food Chem. 2009, 57, 1195-1203. [CrossRef]

18. Basnet, P.; Kadota, S.; Terashima, S.; Shimizu, M.; Namba, T. Two new 2-arylbenzofuran derivatives from hypoglycemic activity-bearing fractions of morus insignis. Chem. Pharm. Bull. 1993, 41, 1238-1243. [CrossRef]

19. Piao, S.J.; Qiu, F.; Chen, L.X.; Pan, Y.; Dou, D.Q. New stilbene, benzofuran, and coumarin glycosides from morus alba. Helv. Chim. Acta 2009, 92, 579-587. [CrossRef]

20. Lee, S.H.; Choi, S.Y.; Kim, H.; Hwang, J.S.; Lee, B.G.; Gao, J.J.; Kim, S.Y. Mulberroside f isolated from the leaves of morus alba inhibits melanin biosynthesis. Biol. Pharm. Bull. 2002, 25, 1045-1048. [CrossRef]

21. Cleland, W. The kinetics of enzyme-catalyzed reactions with two or more substrates or products: Iii. Prediction of initial velocity and inhibition patterns by inspection. Biochim. Biophys. Acta 1963, 67, 188-196. [CrossRef]

22. Naik, R.; Harmalkar, D.S.; Xu, X.; Jang, K.; Lee, K. Bioactive benzofuran derivatives: Moracins a-Z in medicinal chemistry. Eur. J. Med. Chem. 2015, 90, 379-393. [CrossRef] [PubMed]

23. Banks, W.A. Characteristics of compounds that cross the blood-brain barrier. BMC Neurol. 2009,9, S3. [CrossRef] [PubMed]

24. Tanaka, D.; Tsuda, Y.; Shiyama, T.; Nishimura, T.; Chiyo, N.; Tominaga, Y.; Sawada, N.; Mimoto, T.; Kusunose, N. A practical use of ligand efficiency indices out of the fragment-based approach: Ligand efficiency-guided lead identification of soluble epoxide hydrolase inhibitors. J. Med. Chem. 2011, 54, 851-857. [CrossRef]

25. Rezaee, E.; Amrolah, S.M.; Nazari, M.; Tabatabai, S.A. Novel amide derivatives of 3-phenylglutaric acid as potent soluble epoxide hydrolase inhibitors. Mol. Divers. 2019, 1-9. [CrossRef]

26. Kim, J.H.; Ryu, Y.B.; Lee, W.S.; Kim, Y.H. Neuraminidase inhibitory activities of quaternary isoquinoline alkaloids from corydalis turtschaninovii rhizome. Bioorg. Med. Chem. 2014, 22, 6047-6052. [CrossRef]

27. Pettersen, E.F.; Goddard, T.D.; Huang, C.C.; Couch, G.S.; Greenblatt, D.M.; Meng, E.C.; Ferrin, T.E. Ucsf chimera-a visualization system for exploratory research and analysis. J. Comput. Chem. 2004, 25, 1605-1612. [CrossRef]

28. Wallace, A.C.; Laskowski, R.A.; Thornton, J.M. Ligplot: A program to generate schematic diagrams of protein-ligand interactions. Protein Eng. Des. Sel. 1995, 8, 127-134. [CrossRef]

Sample Availability: Samples of the compounds are available from the authors.

(C) 2020 by the authors. Licensee MDPI, Basel, Switzerland. This article is an open access article distributed under the terms and conditions of the Creative Commons Attribution (CC BY) license (http://creativecommons.org/licenses/by/4.0/). 